\title{
BIOLOGIA E TABELA DE VIDA DE FERTILIDADE DE SPODOPTERA FRUGIPERDA (J.E. SMITH) EM LINHAGENS DE MILHO
}

\author{
A.P.A. da Rosa ${ }^{1}$, C.O. Trecha ${ }^{1}$, A.C. Alves ${ }^{2}$, L. Garcia ${ }^{3}$, V.P. Gonçalves ${ }^{2}$ \\ 1Embrapa Clima Temperado, CP403,CEP96001-970,Pelotas, RS, Brasil.E-mail: ana.afonso@cpact.embrapa.br
}

\begin{abstract}
RESUMO
O objetivo deste trabalho foi estudar os aspectos biológicos de Spodoptera frugiperda (J. E. Smith) e elaborar a tabela de vida de fertilidade deste inseto em cinco linhagens de milho provenientes do Programa de Melhoramento de Milho da Embrapa Clima Temperado. Foram determinadas a duração e sobrevivência das fases de ovo, larva, pré-pupa e pupa, peso de pupas, deformações, longevidade, fecundidade e período de pré-oviposição. A linhagem M89611 não permitiu aos insetos realizarem postura. A duração do período de lagarta, pré-pupa, pupa e adultos foram de $10,67,1,22$, 2,13 e 21,33 dias, respectivamente. O peso de pupa para esta linhagem foi de 0,129 e $0,091 \mathrm{~g}$ para fêmeas e machos, respectivamente. As deformações foram de $25 \%$ e a longevidade de 21,3 dias. S. frugiperda aumentou 20,22 vezes a cada geração para a linhagem M89420, com duração média de 37,26 dias e a razão finita de aumento foi de 1,06668. A linhagem M89611 afeta a biologia de $S$. frugiperda, enquanto que, a linhagem M89287 proporciona maior viabilidade das fases de desenvolvimento e a linhagem M89420 proporciona a maior taxa líquida de reprodução.
\end{abstract}

PALAVRAS-CHAVE: Noctuidae, lagarta-do-cartucho, resistência, inseto-praga.

\section{ABSTRACT}

BIOLOGY AND FERTITLITY LIFE TABLE OF SPODOPTERA FRUGIPERDA (J.E. SMITH) IN STRAINS OF CORN. The aim of this work was to study the biology of Spodoptera frugiperda (J. E. Smith) and to elaborate the fertility life table of the insect in five strains of corn from the Programa de Melhoramento de Milho da Embrapa Clima Temperado, in Brazil. The following variables were determined: duration and survival of the egg, larval, pre-pupal and pupal phases, pupal weight, deformation, longevity, fecundity and duration of pre-oviposition. The strain M89611 did not allow the insects to lay eggs. The duration of the periods of larvae, pre-pupae, pupae and adults was 10.67, 1.22, 2.13 and 21.33 days, respectively. The pupal weight for this strain was 0.129 and $0.091 \mathrm{~g}$ for females and males, respectively. The deformations were $25 \%$, and the longevity was 21.3 days. S. frugiperda increased 20.22 times in each generation for the M89420 strain, with an average of 37.26 days, and the finite rate of increase was 1.06668. The strain M89611 affected the biology of $S$. frugiperda, whereas the strain M89287 provided greater viability of the development stages, while strain M89420 provided the highest net reproductive rates.

KEY WORDS: Noctuidae, fall armyworm, resistance, pest.

\section{INTRODUÇÃO}

No Brasil, a área cultivada com as principais culturas de verão no ano agrícola de 2009/2010 foi reduzida em $0,7 \%$ comparada com a safra 2008/2009 e apenas as culturas da soja e de milho, segunda safra, apresentaram crescimento de $7,9 \%$ e $6,3 \%$, respectivamente. Para milho safrinha houveaumento na produção de grãos de $27,1 \%$, ou seja, 4,7 milhões de toneladas (COMPANHIA..., 2010).
Em áreas de várzea, na região Sul do Estado do Rio Grande doSul, onde se cultiva arroz, o milho tem surgido como alternativa fundamental no sistema de rotação de culturas, auxiliando no controle de plantas daninhas como o arroz vermelho (PORTO et al., 1998). $\mathrm{O}$ arroz e o milho apresentam elevada importância sócio-econômica para o Rio Grande do Sul, porém, a incidência de pragas tem comprometido o rendimento ea qualidade da produção, as quais podem determinar importanteimpactoeconômico(FerNANDEsetal.,2003).

${ }^{2}$ Universidade Federal de Pelotas, Pelotas, RS, Brasil.

${ }^{3}$ Universidade da Região de Campanha, Bagé, RS, Brasil.

Arq. Inst. Biol., São Paulo, v.79, n.1, p.39-45, jan./mar., 2012 
Em todo o Hemisfério Ocidental, a lagarta-docartucho, Spodoptera frugiperda (J.E. Smith, 1797) (Lepidoptera: Noctuidae), é considerada a principal praga da cultura do milho (NAGOSH et al., 2007). No Brasil ocorre em todas as regiões produtoras, tanto nos cultivos de verão quanto na segunda safra (Figueredo et al., 2006). A lagarta-do-cartucho se alimenta em todas as fases de crescimento da planta, mas tem preferência por cartuchos de plantas jovens (GIolo et al., 2002). Na cultura do arroz irrigado é conhecida como lagarta-da-folha, causando destruição das plantas novas e desfolha das mais desenvolvidas, sendo o período crítico de ataque compreendido entre a emergência das plantas e a inundação da lavoura, quando o inseto corta o colmo rente ao solo (MARTiNs et al., 2004). As lagartas provenientes das primeiras gerações infestam plantas, causando danos vasculares nos tecidos foliares, levando a uma redução significativa do rendimento (BROOKs et al., 2005).

A cultura do milho, assim como a do arroz, é hospedeira desse inseto-praga, e a proximidade das áreas cultivadas com essas gramíneas tende a intensificar o ataque do inseto aos milharais (GRÜTZMACHER et al., 2000). Dessa forma, a redução na produção causada pelo inseto pode atingir $34 \%$ na cultura do milho, com perdas que podem variar conforme a fase de desenvolvimento da planta atacada, com a cultivar utilizada, local de plantio e mesmo entre áreas adjacentes, segundo as práticas agronômicas adotadas (CRUZ, 1995).

Os danos causados pela lagarta-do-cartucho normalmente são controlados com produtos químicos sintéticos (Lima et al., 2008; BrASIL, 2010) que, além de aumentar os custos de produção, podem poluir o ambiente e deixar resíduos nos alimentos. Diante disso, há interesse em limitar o uso de produtos fitossanitários, estimulando a implementação do manejo integrado de pragas (FIGUEREDO et al., 2006). Estudosjá realizados demonstraram resultados satisfatórios quanto à obtenção de fontes de resistência em linhagens, em material proveniente do programa de Melhoramento de Milho da Embrapa Clima Temperado (CunHa et al., 2008; Afonso-Rosa et al., 2010).

Em programas de manejo integrado de pragas, estudos de tabela de vida de fertilidade são de grande importância para a compreensão da dinâmica populacional de uma espécie, uma vez que permite uma visão integrada das características biológicas de uma população, sob condições ambientais adequadas (COPPEL; Mertins, 1977). De acordo com Silveira Neto et al. (1976), cada indivíduo na tabela de vida apresenta sua própria velocidade de desenvolvimento, longevidade e fecundidade, sendo tais fatores expressos em termos médios da população. A taxa de natalidade e de mortalidade em uma população deinsetosé determinada por várias condições: quali- dade do alimento, temperatura, umidade relativa e fotoperíodo. Tais fatores governam as características biológicas em condições controladas ou não.

Levando em consideração a problemática apresentada e visando fornecer subsídios que contribuam ao Programa de Melhoramento de Milho, quanto à obtenção de fontes de resistência, foram realizados estudos dos aspectos biológicos e da tabela de vida de fertilidade da lagarta-do-cartucho visando gerar informações que propiciem a maximização das estratégias de manejo de supressão populacional para essa praga.

\section{MATERIAL E MÉTODOS}

Os experimentos foram conduzidos no Núcleo de Manejo Integrado de Pragas da Embrapa/UFPel, onde foram utilizadas cinco linhagens de milho provenientes do Programa de Melhoramento de Milho da Embrapa Clima Temperado, sendo estas identificadas por M89374, M89287, M89611, M89601 e M89420, as quais foram cultivadas em casa-devegetação de acordo com as recomendações técnicas para a cultura do milho no estado do Rio Grande do Sul (REUnião..., 2009).

Para cada linhagem, foram individualizadas 100 lagartas recém-eclodidas em tubos de vidro $(2,5 \mathrm{~cm}$ de diâmetro $\times 8,0 \mathrm{~cm}$ de altura), contendo pedaços de folhas de milho de aproximadamente $12 \mathrm{~cm}^{2}$. Os tubos foram tamponados com algodão hidrófugo e mantidos em câmara climatizada à temperatura de $25 \pm 1^{\circ} \mathrm{C}$, umidade relativa de $70 \pm 10 \%$ e fotofase de $14 \mathrm{~h}$. Diariamente, as lagartas foram alimentadas com folhas de milho até atingirem a fase de pré-pupa, quando cessaram a alimentação.

Nafase de pupa, foi realizada a sexagem deacordo com ButT; CANTU (1962) e pesagem 24 horas após a formação, sendo estas mantidas individualmente em tubos de ensaio com um pedaço de papel filtro umedecido até a emergência dos adultos. Casais correspondentes ao mesmo tratamento com diferença de até 48 horas de emergência foram colocados em gaiolas de PVC $(10 \mathrm{~cm}$ de diâmetro $\times 20 \mathrm{~cm}$ de altura), revestidas internamente com papel jornal (substrato de oviposição) sendo fechadas na parte superior com tecido tipo "voile" e os adultos foram alimentados com solução de mel a $10 \%$. Os ovos, retirados diariamente das paredes das gaiolas e do "voile", foram contados com o auxílio de um microscópio estereoscópico e mantidos em recipientes com papel umedecido até a eclosão das lagartas.

Para o estudo dos aspectos biológicos, foram avaliadas as seguintes variáveis: duração e viabilidade das fases de lagarta, pré-pupa, pupa, adulto, pré-oviposição, e o peso de pupas com 24 horas (fêmeas e machos). Para a avaliação da fase adulta, foram formados casais de até 48 horas, onde foi 
determinada a longevidade e a duração do período de pré-oviposição.

A partir dos dados de duração do período de desenvolvimento (ovo-adulto), viabilidade total, razão sexual, período de pré-oviposição, número de ovos por dia e mortalidade diária de fêmeas e machos, foi elaborada a tabela de vida de fertilidade, segundo Silveira Neto et al. (1976). Os parâmetros para a tabela foram intervalo de idade (x), no qual foi tomada a amostra sendo seu valor o ponto médio do intervalo; fertilidade específica (mx) e (lx) taxa de sobrevivência durante o estágio $\underline{x}$.

A partir dos dados gerados foram avaliados os seguintes parâmetros: taxa líquida de reprodução (Ro), o intervalo de tempo entre cada geração (T), a capacidade inata de aumentar em número $\left(\mathrm{r}_{\mathrm{m}}\right)$ e o número de indivíduos adicionados à população, por fêmea, por dia, que darão origem a fêmeas $(\lambda)$. $O$ delineamento experimental foi inteiramente casua-lizado, considerando-se cada inseto uma repetição.

Os dados foram submetidos à análise de variância e as médias foram comparadas pelo teste de Tukey, a 5\% de probabilidade, utilizando-se o programa Genes (CRUZ, 1997). Devido à heterogeneidade de variâncias (Teste de Hartley), dados de duração e peso de pupas foram transformados em $\sqrt{x+0,5}$.

\section{RESULTADOS E DISCUSSÃO}

A duração do período de incubação dos ovos de $S$. frugiperda, provenientes da população alimentada com linhagens de milho variou entre 2,8 e 3,3 dias (Tabela 1) sem, no entanto, haver diferença significativa. Estes resultados foram próximos aos obtidos por VENDRAMIN; FANCELLI (1988) em experimentos visando verificar o efeito de diferentes genótipos de milho no desenvolvimento da lagarta, quando foi observada uma duração variável de 2,6 a 3,0 dias. Os insetos alimentados com a linhagem M89611 não ovipositaram.

A duração da fase larval (Tabela 1) variou de 10,7 a 21,7 dias, sendo que as linhagens M89374 e M89287 apresentaram durações significativamente maiores que as demais. Segundo CunHA et al. (2008), as diferenças na duração da fase larval de $S$. frugiperda podem ser atribuídas a qualidade nutricional de cada linhagem como alimento, já que a duração do ciclo biológico pode ser alterado de acordo com a quantidade e qualidade do alimento consumido na fase larval (PARRA,1991).

No estágio de pré-pupa, a duração média foi de 1,1 a1,3 dias (Tabela1). Pode-seobservarqueosresultados ficaramabaixo dos encontrados por Gioloet al. (2002), que obtiveram período médio desse estágio variando entre 1,8 e 2,4 dias. Porém, foram mais próximos aos observados por BusATO et al. (2004), que obtiveram resultados variando entre 1,2 e 1,5 dias.
A linhagem M89611 proporcionou duração média da fase pupal de 2,1 dias, sendo esta numericamente inferior às demais linhagens. Esses resultados se diferenciaram dos encontrados porGioloet al. (2002), que obtiveram 8,8 dias nas lagartas coletadas no arroz e 12,7 dias quando estas foram nutridas com milho, sendo o período mínimo e máximo de 9 a 17 dias, respectivamente. Foi observada a emergência antecipada das fêmeas em relação aos machos. De acordo com BAVARESCO et al. (2004), a ocorrência de protoginia é um mecanismo que reduz a probabilidade de acasalamento entre indivíduos descendentes da mesma postura, permitindo que as fêmeas, emergindo antes dos machos, voem para outros locais ou, se permanecerem na área, acasalem com os machos provenientes de outras posturas, evitando assim a ocorrência de consanguinidade.

A longevidade dos adultos não diferiu significativamente entre as linhagens, porém, houve variação de duração. Enquanto para a linhagem M89601 (Tabela 1) houve uma duração média de 14,7 dias, a linhagem M89611 teve uma duração de 21,3 dias. Essa diferença, segundo LuginbiLL (1928), pode estar relacionada às características próprias do indivíduo ou à capacidade de conversão do alimento assimilado na fase larval, gerando consequências na longevidade de adultos.

A duração da fase de pré-oviposição (Tabela 1) variou de 0,00 dias na linhagem M89611 a 10,7 dias na linhagem M89601. Não foi constatada diferença significativa entre as linhagens, com exceção da linhagem M89611, porém, os insetos desta linhagem não realizaram posturas. Estes resultados diferiram dos encontrados por BusATo et al. (2004), que obtiveram duração mínima da fase de 2,7 dias em arroz e duração máxima de 3,8 dias em milho. Os mesmos resultados também não corroboraram aqueles encontrados por VELOSO (2010) que obteve duração de 3,4 a 4,8 dias para $S$. frugiperda alimentada com diferentes cultivares de soja.

Levando em consideração os resultados encontrados na linhagem M89611 (Tabela 1) pode se inferir que houve influencia da qualidade do alimento consumido na fase de larval afetando diretamentena aceitação e acesso a cópula, já que esta depende do tamanho do corpo do inseto (PANizzi; PARRA, 2009).

Foram detectadas diferenças significativas quanto ao peso de pupas. Entretanto, pupas fêmeas nas linhagens M89374eM89611(Tabelas 2) não se diferenciaram entre si, sendo estas significativamente diferentes das linhagens M89287, M89601 e M89420. O peso de pupas macho foi 0,086g na linhagem M89374 e o maior peso $0,143 \mathrm{~g}$ foi na linhagem M89420. Os resultados obtidos foram semelhantes aos encontrados por Craig et al. (2000), que encontraram peso de pupas variando desde $0,1377 \mathrm{~g}$ em insetos alimentados com diferentes linhagens de milho. 
Tabela 1 - Duração em dias $(\mathrm{X} \pm \mathrm{EP})$ das fases de desenvolvimento de Spodoptera frugiperda, criada em linhagens de milho. Temperatura: $25 \pm 1^{\circ} \mathrm{C}$; UR: $70 \pm 15 \%$; Fotofase: 14 horas.

\begin{tabular}{|c|c|c|c|c|c|c|}
\hline Linhagens & $\begin{array}{c}\text { Ovo } \\
(X \pm E P)\end{array}$ & $\begin{array}{l}\text { Lagarta } \\
(X \pm E P)\end{array}$ & $\begin{array}{c}\text { Pré-Pupa } \\
(\mathrm{X} \pm \mathrm{EP})\end{array}$ & $\begin{array}{c}\text { Pupa } \\
(X \pm E P)\end{array}$ & $\begin{array}{c}\text { Adulto } \\
(X \pm E P)\end{array}$ & $\begin{array}{c}\text { Pré-oviposição } \\
(X \pm E P)\end{array}$ \\
\hline \multirow{3}{*}{ M89374 } & $2,8 \pm 0,11 a^{1}$ & $21,7 \pm 1,32 \mathrm{a}^{1}$ & $1,2 \pm 0,07 a^{1}$ & $9,7 \pm 0,26 a b^{1}$ & $20,5 \pm 1,33 \mathrm{a}^{1}$ & $9,4 \pm 1,14 b^{1}$ \\
\hline & $(2-3)^{2}$ & $(8-49)^{2}$ & $(1-2)^{2}$ & $(7-12)^{2}$ & $(4-32)^{2}$ & $(3-15)^{2}$ \\
\hline & {$[18]^{2}$} & {$[98]^{2}$} & {$[38]^{2}$} & {$[31]^{2}$} & {$[28]^{2}$} & {$[18]^{2}$} \\
\hline \multirow{3}{*}{ M89287 } & $3,1 \pm 0,11 \mathrm{a}$ & $20,7 \pm 1,21 \mathrm{a}$ & $1,3 \pm 0,09 a$ & $10,1 \pm 0,22 \mathrm{a}$ & $21,1 \pm 1,48 \mathrm{a}$ & $6,9 \pm 0,48 b$ \\
\hline & $(2-4)$ & $(6-39)$ & $(1-4)$ & $(7-13)$ & $(3-36)$ & $(4-12)$ \\
\hline & [26] & [100] & [47] & {$[40]$} & {$[32]$} & [26] \\
\hline \multirow{3}{*}{ M89611 } & $0,0 \pm 0,00 \mathrm{~b}$ & $10,7 \pm 0,82 \mathrm{c}$ & $1,2 \pm 0,15 \mathrm{a}$ & $2,1 \pm 1,41 b$ & $32,3 \pm 0,80 a$ & $0,0 \pm 0,00 \mathrm{a}$ \\
\hline & $(0)$ & $(5-36)$ & $(1-2)$ & $(6-10)$ & $(18-48)$ & $(0)$ \\
\hline & [6] & [99] & [9] & [6] & [6] & [6] \\
\hline \multirow{3}{*}{ M89601 } & $3,3 \pm 0,13 a$ & $14,5 \pm 0,76 b c$ & $1,1 \pm 0,05 a$ & $9,2 \pm 0,22 \mathrm{ab}$ & $14,7 \pm 1,94 a$ & $10,7 \pm 1,39 b$ \\
\hline & (3-4) & $(8-37)$ & $(1-2)$ & $(8-11)$ & $(5-28)$ & $(2-19)$ \\
\hline & [14] & [100] & [20] & [18] & [18] & [14] \\
\hline \multirow{3}{*}{ M89420 } & $3,2 \pm 0,18 \mathrm{a}$ & $14,6 \pm 0,82 b$ & $1,2 \pm 0,10 \mathrm{a}$ & $9,7 \pm 0,49 a b$ & $19,5 \pm 2,75 a$ & $8,3 \pm 1,25 a$ \\
\hline & $(3-4)$ & $(9-43)$ & $(1-3)$ & $(7,14)$ & $(3-42)$ & $(5-11)$ \\
\hline & 6 & [95] & [23] & [22] & & {$[6]$} \\
\hline $\mathrm{CV}(\%)$ & 7,18 & 24,38 & 11,45 & 7,18 & 23,70 & 23,48 \\
\hline
\end{tabular}

${ }^{1}$ Médias seguidas pela mesma letra na coluna não diferem entre si, ao nível de $5 \%$ de probabilidade, pelo teste de Tukey. ${ }^{2}$ Valores entre parênteses expressam o intervalo de variação e entre colchetes o número de observações [n].

Tabela 2 - Peso (g) de pupas fêmeas e machos, deformações (\%) e longevidade em dias de Spodoptera frugiperda criadas em folhas de linhagens de milho. Temperatura: $25 \pm 1{ }^{\circ} \mathrm{C}$; UR: $70 \pm 15 \%$; Fotofase: 14 horas.

\begin{tabular}{|c|c|c|c|c|}
\hline Linhagens & $\begin{array}{c}\text { Peso Fêmeas }(\mathrm{g}) \\
(\mathrm{X} \pm \mathrm{EP})\end{array}$ & $\begin{array}{c}\text { Peso Machos (g) } \\
(\mathrm{X} \pm \mathrm{EP})\end{array}$ & $\begin{array}{c}\text { Deformações } \\
(\%)\end{array}$ & $\begin{array}{c}\text { Longevidade } \\
\text { (dias) }\end{array}$ \\
\hline \multirow{3}{*}{ M89374 } & $0,075 \pm 0,01 b^{1}$ & $0,086 \pm 0,01 c^{1}$ & \multirow{3}{*}{11,4} & \multirow{3}{*}{45,7} \\
\hline & $(0,064-0,098)^{2}$ & $(0,06-0,115)^{2}$ & & \\
\hline & {$[19]^{2}$} & {$[16]^{2}$} & & \\
\hline \multirow{3}{*}{ M89287 } & $0,019 \pm 0,01 a$ & $0,132 \pm 0,01 \mathrm{ab}$ & \multirow{3}{*}{18,2} & \multirow{3}{*}{42,9} \\
\hline & $(0,085-0,158)$ & $(0,017-0,166)$ & & \\
\hline & [19] & {$[25]$} & & \\
\hline \multirow{3}{*}{ M89611 } & $0,088 \pm 0,01 b$ & $0,091 \pm 0,01 b c$ & \multirow{3}{*}{25,0} & \multirow{3}{*}{21,3} \\
\hline & $(0,072-0,105)$ & $(0,076-0,105)$ & & \\
\hline & [6] & [2] & & \\
\hline \multirow{3}{*}{ M89601 } & $0,124 \pm 0,01 \mathrm{a}$ & $0,142 \pm 0,01 a$ & \multirow{3}{*}{10,0} & \multirow{3}{*}{44,0} \\
\hline & $(0,078-0,158)$ & $(0,065-0,201)$ & & \\
\hline & [9] & {$[11]$} & & \\
\hline \multirow{3}{*}{ M89420 } & $0,134 \pm 0,01 \mathrm{a}$ & $0,143 \pm 0,01 a$ & \multirow{3}{*}{13,6} & \multirow{3}{*}{37,5} \\
\hline & $(0,106-0,158)$ & $(0,121-0,171)$ & & \\
\hline & [10] & [12] & & \\
\hline $\mathrm{CV}(\%)$ & 1,44 & 1,68 & - & - \\
\hline
\end{tabular}

${ }^{1}$ Médias seguidas pela mesma letra na coluna não diferem entre si, ao nível de $5 \%$ de probabilidade, pelo teste de Tukey. ${ }^{2}$ Valores entre parênteses expressam o intervalo de variação e entre colchetes o número de observações [n].

Foram observadas deformações em pupa e em adultos de 10,0 e 25,0\%, respectivamente (Tabela 2). O maior índice de deformação foi constatado em adultos com asas tortas e curtas. Essas deformações podem ser oriundas de problemas na alimentação, pois a deficiência de ácidos graxos, principalmente linoleico e linolênico, podem originar adultos com asas deformadas (PARRA, 2001).

Ociclo biológico completo de S. frugiperda (Tabela 2) variou de 21,3 a 45,7 dias, resultados estes inferiores aos encontrados por BUSATO et al. (2004) para $S$. frugiperda e por BAVARESCO et al. (2004), cuja duração média de Spodoptera cosmioides (Walk.) em diferentes dietas variou de 49,1 a 53,4 dias para lagartas alimentadas em dieta artificial. Esses resultados podem estar demonstrando algum efeito cumulativo do alimento ingerido pela lagarta-do-cartucho, durante seu desenvolvimento total (VIANA; POTENZA, 2000).

Dentre as linhagens oferecidas e que proporcionaram asfêmeas realizarem postura a fecundidade diária (Tabela 3) foi de 18,8 a 117,8 ovos por/fêmea para as linhagens M89374eM89420 respectivamente, enquanto para fecundidade total variou de 1666,0 ovos / fêmea para a linhagem M89374 e 3577,0 para a M89287. 
A maior variabilidade no número de ovos foi verificada na linhagem M89420 (44,5\%) (Tabela 3), sendo estes resultados considerados baixos quando comparados aos encontrados por BURTON; PERKINS (1972), que constataram uma viabilidade em torno de $90,2 \%$, no entanto, utilizando dieta artificial.

A viabilidade da fase larval representa um dos fatores mais importantes do crescimento populacional (DAHMS, 1972). Neste trabalho a viabilidade das lagartas variou de 11,0 a $46,0 \%$ (Tabela 4 ). A viabilidade observada foi baixa quando comparada com a encontrada por Giolo et al. (2002), que obtiveram valores entre 90,7 e 96,7\%, no entanto, em arroz. Também não corroborou com a viabilidade registrada por VELOSO (2010), que obteve resultados de 66,7 a $86,7 \%$ em lagartas alimentadas com folhas de soja. Também se constatou que os valores encontrados para a viabilidade de larval são inferiores aos encontrados em outros hospedeiros, incluindo milho $(85,0 \%)$, sorgo granífero $(77,0 \%)$, sorgo selvagem $(80,0 \%)$, soja $(83,0 \%)$ e braquiária $(68,0 \%)$ (SÁ et al., 2009). Em soja, S. cosmioides apresentou somente3,9\% de viabilidade (BAVARESCO et al., 2003).

Na fase de pré-pupa a menor viabilidade $81,8 \%$ (Tabela 4) foi da linhagem M89611, enquanto a maior viabilidade foi de 100,0\% nas linhagens M89287 e M89601, sendo próximos aos encontrados por Giolo et al. (2002), que obtiveram uma viabilidade de 93,4 a 97,9\% em pré-pupas de $S$. frugiperda quando alimentadas em cultivares de arroz. CunHA et al. (2008) observaram viabilidade de pupas entre 49,9 a $91,4 \%$, corroborando os resultados encontrados neste trabalho. Nesse sentido a redução da viabilidade de pupas na linhagem M89611,pode estar associada a algum mecanismo de resistência que interferiu negativamente na nutrição de lagartas, pois, segundo SCRIBER; SLANSKY JUNIOR (1981), a fisiologia, o compor- tamento, a ecologia e a evolução de um inseto são afetadas por fatores nutricionais.

A viabilidade total na linhagem M89611 foi 0\% (Tabela 4), evidenciando a importância do alimento ingerido nas fases iniciais da vida do inseto, pois aspectos qualitativos equantitativos devem preencher corretamente as necessidades nutricionais dos insetos, para que o desenvolvimento seja satisfatório até a fase adulta (PANizzi; PARRA, 2009).

A taxa líquida de reprodução $\left(R_{\mathrm{o}}\right)$, ou seja, a capacidade da população aumentar em número a cada geração foi de 4,5 vezes (Tabela 5) para a linhagem M89287, enquanto para a linhagem M89420 o aumento da população foi de 20,2 vezes, podendo esta última linhagem ser considerada a mais adequada para o desenvolvimento da lagarta-do-cartucho. Embora estes valores estejam bem abaixo dos encontrados por Busato et al. (2004), que obtiveram um Ro de 361,5 para a população alimentada com milho em áreas adjacentes e de 504,6 em populações alimentadas com arroz de áreas isoladas.

Tabela 3 - Fecundidade diária e total de ovos de Spodopetra frugiperda em linhagens de milho. Temperatura: $25 \pm 1^{\circ} \mathrm{C}$; UR: $70 \pm 15 \%$; Fotofase: 14 horas.

\begin{tabular}{lcc}
\hline Linhagens & Fecundidade diária & Fecundidade total \\
\hline M89374 & $18,8 \mathrm{~b}^{1}$ & $1666,0 \mathrm{~b}$ \\
M89287 & $19,4 \mathrm{~b}$ & $3877,0 \mathrm{a}$ \\
M89611 & $0,0 \mathrm{c}$ & $0,0 \mathrm{c}$ \\
M89601 & $40,4 \mathrm{~b}$ & $2850,0 \mathrm{ab}$ \\
M89420 & $117,8 \mathrm{a}$ & $1291,0 \mathrm{ab}$ \\
\hline CV $(\%)$ & 47,21 & 41,79 \\
\hline
\end{tabular}

${ }^{1}$ Médias seguidas pela mesma letra na coluna não diferem entre si, ao nível de $5 \%$ de probabilidade, pelo teste de Tukey.

Tabela 4 - Viabilidade (\%) das fases de desenvolvimento da Spodoptera frugiperda, em linhagens de milho. Temperatura: $25 \pm 1^{\circ} \mathrm{C}$; UR: $70 \pm 15 \%$; Fotofase: 14 horas.

\begin{tabular}{|c|c|c|c|c|}
\hline \multirow{2}{*}{ Linhagens } & Ovo & Lagarta & Pré-Pupa & Pupa \\
\hline & \multicolumn{4}{|c|}{ 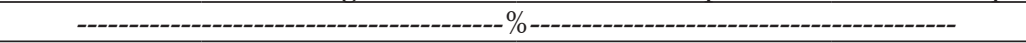 } \\
\hline M89374 & 22,6 & 38,0 & 92,0 & 88,0 \\
\hline M89287 & 39,9 & 46,0 & 100,0 & 78,0 \\
\hline M89611 & 0,0 & 11,0 & 81,8 & 66,7 \\
\hline M89601 & 22,0 & 20,0 & 100,0 & 90,0 \\
\hline M89420 & 44,5 & 24,0 & 96,0 & 78,0 \\
\hline
\end{tabular}

Tabela 5 - Taxa líquida de reprodução (Ro), duração média de uma geração (T), capacidade inata de aumentar em número (rm) e razão finita de aumento (l) de Spodoptera frugiperda, em linhagens de milho. Temperatura: $25 \pm 1^{\circ} \mathrm{C}$; UR: $70 \pm 15 \%$; Fotofase: 14 horas.

\begin{tabular}{lcccc}
\hline Linhagens & Ro & T & Rm & $\lambda$ \\
\hline M89374 & 6,65 & 60,09 & 0,03153 & 1,03203 \\
M89287 & 4,54 & 54,92 & 0,02755 & 1,02793 \\
M89601 & 6,75 & 53,75 & 0,03553 & 1,03617 \\
M89420 & 20,22 & 37,26 & 0,06455 & 1,06668 \\
\hline
\end{tabular}


Quanto à duração média de uma geração $(\mathrm{T})$, a linhagem M89420 e a M89374 manifestaram, respectivamente, 37,3 e 60,1 dias. Estes resultados foram próximos aos encontrados por BAVARESCOetal. (2004), que encontraram valores variando entre 49,1 a 53,4 dias para $S$. cosmioides em dieta artificial.

A taxa intrínseca de crescimento $r_{m}$ para as linhagens M89287 e M89420 foi de 0,02755 e 0,06455, respectivamente(Tabela5). A taxa finita de aumento ( $\lambda$ ) e/ou taxa de crescimento diário da população (Tabela 5) não apresentou diferenças significativas entre as linhagens.

\section{CONCLUSÕES}

A linhagem M89611 afetaabiologia de S. frugiperda, enquanto que a linhagem M89287 proporciona maior viabilidade das fases de desenvolvimen-to e a linhagem M89420 proporciona a maior taxa líquida de reprodução.

\section{REFERÊNCIAS}

AFONSO-ROSA, A.P.; TRECHA, C.O.; GARCIA, L.; ALVES, A.C.; MANSKE, E.; GONÇALVES, V.P. Seleção de linhagens de milho resistentes a Spodoptera furgiperda (J.E. Smith, 1797) (Lepidoptera: Noctuidae) para áreas de várzeas no Rio Grande do Sul. Trabalho apresentado no CONGRESSO BRASILEIRO DE ENTOMOLOGIA, 23., 2010, Natal. Resumo, 1 CD_ROM.

BAVARESCO, A.; GARCIA, M.S.; GRUTZMACHER, A.D.; RINGENBERG, R.; FORESTI, J. Biologia comparada de Spodoptera cosmioides (WALK.) (Lepidoptera: Noctuidae) em cebola, mamona, soja e feijão. Ciência Rural, v.33, n.6, p.993-998, 2003.

BAVARESCO, A.; GARCIA, M.S.; GRÜTZMACHER, A.D.; RINGENBERG, R.; FORESTI, J. Adequação de uma dieta artificial para a criação de Spodoptera cosmioides (Walk.) (Lepidoptera: Noctuidae) em laboratório. Neotropical Entomology, v.33, n.2, p.155-161, 2004.

BRASIL. Ministério da Agricultura Abastecimento e Pecuária - Disponível em: http:<www.agricultura.gov. br/ >. Acesso em: 20 out. 2010.

BUSATO, G.R.; GRÜTZMACHER, A.D.; GARCIA, M.S.; GIOLO, F.P.; ZOTTI, M.J.; MAGALHÃES, T.R. Tabela de vida de fertilidade de populações de Spodoptera frugiperda (J.E. Smith, 1797) (Lepidoptera: Noctuidae) em folhas de milho e arroz irrigado. Revista Brasileira de Agrociência, v.10, n. 4, p.449-455, 2004.

BUTT, B.A.; CANTU, E. Sex determination of lepidopterous pupae. Waschington: USDA, 1962. 7p.
BURTON, R.L.; PERKINS, W.D. WSB, a new laboratory diet for the corn ear worm and the fall armyworm. Journal of Economic Entomology, v.65, p.385-386, 1972.

BROOKS, T.D.; WILLOCOX, C.M.; WILLIAMS, P.W; BUCKLEY, M.P. Quantitative trait loci conferring resistance to fall army wormand southwestern corn borer leaf feeding damage. Crop Science, n.45, p.24302434, 2005.

COMPANHIA NACIONAL DE ABASTECIMENTO. (Brasil). Levantamento de Safra. $12^{\circ}$ Levantamento de Grãos 2010. Disponível em: < http:/ / www.conab.gov. br/>. Acesso em: 5 out. 2010.

COPPEL, H.C.; MERTINS, J.W. Biological insect pest suppression. New York: Springer-Verlag, 1977. 314p.

CRAIG, A.A.; RICHARD L. W.; BILLY, R.; WISEMAN, WILLIAM, H.W.; FRANK, M.D. Conventional resistance of experimental maize lines to corn earworm (Lepidoptera: Noctuidae), fall armyworm (Lepidoptera: Noctuidae), southwestern corn borer (Lepidoptera: Crambidae), and sugarcane borer (Lepidoptera: Crambidae). Journal of Economiv Entomology, v.93, n.3, p.982-988, 2000.

CRUZ, C.D. Programa Genes - Aplicativo computacional em genética e estatística. Disponível em: <www.ufv/ dbg/genes/genes.htm 2010>. Acesso em 5 out. 2010.

CRUZ, I. A lagarta-do-cartucho na cultura do milho. Sete Lagoas: EMBRAPA-CNPMS, 1995. 45 p. (Circular técnica, 21).

CUNHA, U.S.; MARTINS, J.F.S.; PORTO, P.M.; GARCIA, S.M.; BERNARDI, O.; TRECHA, O.C.; BERNARDI, D.; JARDIM, O.E.; BACK, U.C.E. Resistência de milho para cultivo em várzeas subtropicais à lagarta-do-cartucho Spodoptera frugiperda. Ciência Rural, v.38, n.4, p.1125- 1128, 2008.

DAHMS, R.G. The role of host plant resistance in integrated insect control. In: JOTWANI, M.G.; YOUNG, W.R. (Eds.). Control of sorghum shoot fly. New Delhi: Oxford \& IBH, 1., , 1972. p.152-167.

FERNANDES, O.D.; PARRA, J.R.P.; NETO, F.A.; PICOLI, R.; BORGATTO, F.A.; DEMÉTRIO, G.B.C. Efeito do milho geneticamente modificado MON810 sobre a lagarta-do-cartucho Spodoptera frugiperda (J. E. Smith, 1797) (Lepidoptera: Noctuidae). Revista Brasileira de Milho e Sorgo, v.2, n.2, p.25-35, 2003.

FIGUEREDO, M. de L.C.; DIAS-MARTINS, A.M.P.; CRUZ, I. Relação entre a lagarta-do-cartucho e seus agentes de controle biológico natural na produção de milho. Pesquisa Agropecuária Brasileira, v.41, n.12, p.16931698, 2006.

GIOLLO, F.P.; GRUTZMACHER, A.D.; GARCIA, M.S.; BUSATO, G.R. Parâmetros biológicos de Spodoptera 
frugiperda (J. E. Smith, 1797) (Lepidoptera: Noctuidae) oriundas de diferentes localidades e hospedeiros. Revista Brasileira de Agrociência, v.8, p.221-224, 2002.

GRÜTZMACHER, A.D.; MARTINS, J.F. da S.; CUNHA, U.S. da; PARFITT, J.M.B. In: Insetos-praga das culturas do milho e sorgo no agroecossistema de várzea. In: PARFITT, J.M.B. (Ed.). Produção de milho e sorgo em várzea. Pelotas: Embrapa Clima Temperado, 2000. p.87-102.

LIMA, J.F.M.; GRÜTZMACKER, D.A.; CUNHA, U.S.; PORTO, P.M.; MARTINS, S.J.F.; DALMASO, O.G. Ação de inseticidas naturais no controle de Spodoptera frugiperda (J.E. Smith, 1797) (Lepidoptera: Noctuidae) em milho cultivado em agroecossistema de várzea. Ciência Rural, v.38, n.3, p.607-613, 2008.

LUGINBILL, P.H. The fall armyworm. Washington, USDA, 1928. 73p. (Technical Bulletin, n.34).

MARTINS, J.F.S.; GRÜTZMACHER, A.D.; CUNHA, U.S. da Descrição e manejo integrado de insetos-praga em arroz irrigado. In: GOMES, A. da S.; MAGALHÃES JUNIOR, A.M. (Ed.). Arroz irrigado no Sul do Brasil. Brasília: Embrapa, 2004. Cap.19, p.635-675. (Informações Tecnológicas).

NAGOSHI, R.N.; SILVIE, P.; MEAGHER, L.R.; LOPEZ, J.; MACHADO, V. Identification and Comparison of fall armyworm (Lepidoptera: Noctuidae) host strains in Brazil, Texas, and Florida. Annals of the Entomological Society of America, v.100, n.3, p.394-402, 2007.

PANIZZI, R.A.; PARRA, J.R.P. Consumo e utilização do alimento para o crescimento da fase larval. In: (Ed.). Bioecologia e nutrição de insetos. Brasília: Embrapa Informação Tecnológica, 2009. Cap.2, p.65- 90 .

PARRA, J.R.P. Consumo e utilização de alimento por insetos. In: PANIZZI, A. R.; PARRA, J.R.P. (Ed). Ecologia nutricional e suas implicações no manejo de pragas. São Paulo: Manole, 1991. p.9-65.

PARRA, J.R.P. Técnicas de criação de insetos para programas de controle biológico. 6.ed. Piracicaba: ESALQ/FEALQ, 2001. 134p.
PORTO, M.P.; SILVA, S.D.A.; WINKLER, E.I.G.; SILVA, C.A.S.; PARFITT, J.M.B. Milho em várzeas de clima temperado na região sul do Brasil: cultivares e manejo de solo e água. Pelotas: Embrapa Clima Temperado, 1998. 31p. (Embrapa Clima Temperado: Circular Técnica, 6).

REUNIÃO TÉCNICA ANUAL DO MILHO, 54; REUNIÃO TÉCNICA ANUAL DO SORGO, 37, 2009, Veranópolis. Indicações Técnicas para o cultivo de milho e sorgo no Rio Grande do Sul: 2009/2010, 2010/2011. Veranópolis: Fepagro, 2009. 179p. Organizado por Lia Rosane Rodrigues, José Paulo Guadagnin e Marilda Pereira Porto.

SÁ, V.G.M.; FONSECA, B.V.C.; BOREGAS, K.G.B.; WAQUIL, J.M. Sobrevivência e desenvolvimento larval de Spodoptera frugiperda (J. E. Smith) (Lepidoptera: Noctuidae) em hospedeiros alternativos. Neotropical Entomology, v.38, n.1, p.108-115, 2009.

SCRIBER, J.M.; SLANSKY, JUNIOR, F. The nutritional ecology of immature insects. Annual Review of Entomology, v.26, p.183-211, 1981.

SILVEIRA NETO, S.; NAKANO, A.; BARBIN, D.N.A.V. Nova. Manual de ecologia dos insetos. São Paulo: Agronômica Ceres, 1976. 419p.

VELOSO, S.E. Resistência de cultivares de soja a Spodoptera frugiperda (J. E. Smith) (Lepidoptera: Noctuidae). 2010. 56f. Dissertação (Mestrado em Agronomia - Área de Concentração: Sistemas de Produção) - Universidade Estadual Paulista. Faculdade de Engenharia de Ilha Solteira, Ilha Solteira, 2010.

VENDRAMIM, J.D.; FANCELLI, M. Efeito de genótipos de milho na biologia de Spodoptera frugiperda (J.E. Smith, 1797) (Lepidoptera: Noctuidae). Anais da Sociedade Entomológica do Brasil, v.17, p.141- 150, 1988.

VIANA, P.A.; POTENZA, M.R. Avaliação de antibiose e não-preferência em cultivares de milho selecionados com resistência à lagarta-do-cartucho. Bragantia, v.59, n.1, p.27-33, 2000.

Recebido em 8/11/10

Aceito em 8/11/11 